\title{
Xamanismo e a saúde: abordagem sociocultural
}

\author{
Aline Soares de Souza ${ }^{1,2}$ \\ 1. Universidade Federal de Roraima. Programa de Pós - Graduação em Ciências da Saúde (PROCISA). Campus \\ Paricarana. Av. Cap. Ene Garcez, 2413. Bairro Aeroporto. Cep: 69310-000 Boa Vista / RR
}

2. Autor para correspondência: malu.aline@gmail.com

Recebido em: 26/09/2014 Aceito em: 12/12/2014 Publicado online em PDF: 22/12/2014.

RESUMO

Xamanismo e a saúde: abordagem sociocultural. No contexto atual de um mundo globalizado, o xamanismo pode ser interpretado como algo primitivo, arcaico ou ultrapassado, principalmente quando relacionado à área de saúde. O presente estudo é uma revisão bibliográfica sobre os diferentes que se ateve demonstrar o universo xamânico como um sistema cosmológico e cosmopolítico. Observou-se o papel central do xamã presente não somente nos rituais religiosos, mas também na manutenção das organizações nas suas sociedades. Também é destacada a função primordial do xamã nas técnicas de diagnóstico e cura de doenças físicas ou mentais e o uso de plantas medicinais na manutenção, prevenção e tratamento da saúde. A cura xamânica passa por um processo complexo de crença e efeito psicossomático, que não resolve apenas problemas físicos, mas envolve uma dinâmica existencial universal.

PALAVRAS-CHAVE: Xamã; Cura; Cosmológico; Simbólico; Medicina Tradicional.

\begin{abstract}
Shamanism and health: sociocultural approach. In the current context of a globalized world, shamanism can be interpreted as something primitive, archaic or outdated, especially when related to health. This study is a literature review on the different adhered to demonstrate the shamanic universe as a cosmological and cosmopolitical system. It shows the central role of shaman present not only in religious rituals but also in the maintenance of organizations in their societies. Also shows the primary role of the shaman on the diagnostic techniques and healing of physical or mental illness and the use of medicinal plants in the maintenance, prevention and treatment of health is highlighted. The Shamanic healing goes through a complex process of belief and psychosomatic effect that not only solve physical problems, but involves a universal existential dynamics.
\end{abstract}

KEYWORDS: Shaman; Healing; Cosmological; Symbolic; Traditional Medicine.

\section{INTRODUÇ̃̃O}

No contexto atual de um mundo globalizado, que, conforme Helman (2009)', é a "união de fatores políticos, sociais, culturais e econômicos" e onde o novo é sempre aceito com ares de evolução, o tema xamanismo pode ser interpretado como algo primitivo, arcaico ou ultrapassado. Esta interpretação pode ser mais destacada quando nos referimos á área de saúde.
Entretanto, observa-se que o xamanismo presente no Brasil, também tido como pajelança, está fortemente inserido no contexto atual, tendo em vista a diversidade sociocultural presente no país. Para discutir a importância sociocultural e o conceito de xamanismo este trabalho se concentrou nas características sociais, culturais e simbólicas de um modelo inserido nas visões cosmológicas, que traz uma reflexão importante sobre saúde.

\footnotetext{
${ }^{1}$ Cecil Helman, em seu livro, estudou o conceito de globalização e as inter-relações com saúde, doença e cultura, evidenciando que "as culturas estão interagindo cada vez mais umas com as outras", tornando possível a disseminação do conhecimento sobre doenças e práticas de tratamento. Helman lembra os efeitos positivos e negativos desta troca de informações A globalização e sua relação com a saúde é vista de forma simples por Helman: "pode ter o efeito positivo de propagar informações sobre a pesquisa médica mais recente".
} 
O xamanismo representa o mais difundido e antigo sistema metodológico de tratamento da mente e do corpo que a humanidade conheceu. Dados arqueológicos e etnológicos dizem que os métodos xamânicos datam cerca de 40 a 50 mil anos, sendo que o primeiro tratado vem da Sibéria. Acreditam-se os homens/xamãs teriam emigrado durante as grandes glaciações seguindo rebanhos de renas. Estes teriam atravessado pelo estreito de Bering ou por outra ponte terrestre que ligava os dois continentes e se espalharam pelo mundo (Artese 2005).

O xamanismo, denominação que vem do russo, tungue (saman), tem semelhança com o termo sânscrito sramana ${ }^{2}$ que significa aquele que é inspirado pelos espíritos. $\mathrm{O}$ termo propriamente dito é derivado de um acontecimento religioso siberiano e centroasiático. Porém a sua denominação é usada ainda hoje em todo mundo para definir um conjunto de crenças ancestrais que estabelecem contato com uma realidade invisível, ou estados diferenciados de consciência, a fim de obter poder, equilíbrio, conhecimentos e saúde individual ou coletiva.

Segundo Artese (2005), o xamanismo é a "Jornada da Consciência", um legado da humanidade além das fronteiras dos países, credos, raças, filosofias.

O xamanismo apresenta um conceito muito maior, globalizante e dinâmico. Assim, este estudo tem o intuído principal é trazer o leitor a um passeio inicial sobre o contexto xamânico e seu universo cósmico e simbólico, onde estão inseridos seres visíveis e invisíveis de forma socialmente organizada e politicamente estruturada.

Para esta discussão foi realizada uma revisão bibliográfica nas principais bases de dados nacionais e estrangeiras entre os anos de 2010 e 2014 e em obras especializadas sobre o assunto. A seguir é apresentado o papel do xamã como personagem principal, uma análise contexto sociocultural do xamanismo e a sua relação com a medicina tradicional.

\section{O XAMÃ}

Durante muitos anos, e ainda atualmente sobre alguns olhares, o xamanismo foi conceituado como uma prática arcaica, mágica, ou tendo características de personagens psicóticos, ou ainda tido como religião. No xamanismo existe um personagem central, o Xamã, também conhecido como chefe cerimonial, sacerdote, pajé, profeta, adivinho, curador, entre outros nomes, é um mediador entre o mundo humano e o mundo dos espíritos que usa a magia para controle social. No século passado, xamã tornou-se um termo universal para indicar pessoas místicas, que faziam viagens mágicas, sendo "travestis" e "histéricos" (Langdon 1996a,b). Esse mágico experimenta o êxtase e obtém poderes mágicos que permite sua comunicação com espíritos e animais.

Na visão de Sams (1997), o verdadeiro xamã é um grande guerreiro, corajoso e capaz de vencer seus medos e encarar a morte de perto:

\footnotetext{
“'Um xamã é aquele indivíduo que caminhou até os portais do seu inferno pessoal e teve coragem de entrar. Um verdadeiro Xamã é aquele que enfrentou e venceu os demônios auto concebidos do medo, da insanidade, da solidão, da auto importância e dos vícios ao passar pela gama de mortes do Xamã" (Sams 1997).
}

Os poderes "mágicos" destes xamãs são alcançados de diversas formas conforme as diferentes culturas. Em alguns povos indígenas, os poderes xamânicos são adquiridos através de substâncias ditas mágicas (tabaco, fumaça, plantas psicoativas, etc).

$\mathrm{Na}$ visão que associa xamanismo à utilização de plantas psicotrópicas vemos que se originou uma nova consciência religiosa que difundiu o xamanismo presente em práticas de cultos da União do Vegetal, que usa plantas como o Mariri e a Chacrona, e Santo Daime, no Brasil (Langdon 2012).

Eliade (1964 apud Langdon 1996a), buscou caracterizar o que seria o xamanismo "puro". $\mathrm{Na}$ sua concepção o xamã tem um chamado, uma vocação, que se manifesta e torna-se objetivo de aprendizagem, que é secreta e tradicional. Tem-se então um xamã como um sacerdote que possui vocação para empregar seus poderes para um bem social e pessoal.

\section{XAMANISMO: ENFOQUE SOCIOCULTURAL}

\section{Conceito cosmológico}

\footnotetext{
2. Informação retirada do texto Divagações Xamânicas de Léo Artese, 2005.
} 
O conceito cosmológico de xamanismo confere um aspecto sociocultural ao tema e direciona o poder xamânico para a explicação coletiva da existência, não negando o aspecto sagrado do rito. Esse sistema é fundamental para organizar as sociedades dele pertencentes.

O poder presente no sistema de xamanismo constitui em uma organização política e social que traz beneficio aos autores sociais. Nesse sentido o papel do xamã é ressaltado em relação ao mundo invisível: "[...] capazes de ver os nãos humanos como estes se vêem (como humanos), os xamãs, ocupam o papel de interlocutores ativos no diálogo cósmico. Eles são como diplomatas que tomam a seu cargo as relações interespécies, operando em uma arena cosmopolítica onde se defrontam as diferentes categorias socionaturais." (Castro, 2002).

A concentração desse poder se manifesta através de ritos sociais individuais ou coletivos. Por isso é devida a importância do xamã como mediador entre o mundo espiritual e material e entre as relações sociais individual e coletivamente, tendo papel social positivo, sem estigma, construído culturalmente. Existe essa significância cultural no poder do xamã, fazendo com que haja a manutenção da tradição tribal e do código moral.

Castro (2002) define um espaço chamado de cosmopolítico, que é irredutível a um mundo exclusivamente humano, onde forças macroscópica/visíveis e microscópica/ invisíveis povoam um universo cósmico, sobrenatural. $\mathrm{O}$ autor faz uma referencia à realidade Amazônica:

"[...] quadros sociológicos mais vastos são, naquela região [Amazônica], realmente vastos, incluindo muito mais que apenas outros grupos locais da mesma família étnica ou linguística - e não me refiro aqui a outras "tribos", ou aos grandes e heterogêneos sistemas regionais précolombianos. Os quadros sociológicos vão tão longe quanto as sociologias nativas vão; e essas mobilizam uma vária multidão de outros, humanos como não-humanos, multidão que não é nem distribuível, nem totalizável de modo evidente" (Castro 2002).

Andrade (2007) em sua tese sobre o xamanismo na região do baixo Oiapoque (AP) apresenta os povos indígenas Galibi-Kalinã, Galibi-Marworno, Palikur e Karipuna compartilhando uma cosmologia dividida em mundos distintos, caracterizado por pessoas e não humanos, de domínios comumente chamados pelos pajés que visualizam os diferentes mundos que são habitados.

O xamanismo, principalmente Amazônico, revela-se uma atividade de tradução que pode ser transportada do nível sobrenatural para o sociopolítico, visto que pode implicar a apreensão local, um ponto de vista, de uma rede de relações mais globais, como referiu Cunha (1998).

\section{Sistema sociocultural e simbólico}

$\mathrm{Na}$ concepção destacada por Langdon (1996a,b), o xamanismo torna-se concreto através do rito, mito, arte e manifestação simbólica, não necessariamente precisa estar associado a presença de um xamã, porém esse tem seu papel de mediador e carrega importância social e política, além de ser o principal autor da cura.

Nesse aspecto o xamanismo funciona de forma simbólica, pois a cultura que o envolve é uma teia de significados, um sistema simbólico coletivo, público e expressivo, portando é fundamental para organizar o universo e definir seu lugar frente ao mundo.

Assim, essa concepção está guiada por um conceito dinâmico de cultura, que utiliza a simbologia dos ritos como forma de prepará-los para enfrentar emoções e sentimentos presentes, de forma individual ou coletiva. Normalmente após o rito há uma "mudança de vida", "mudança de pensamento", atuando frente ao mundo com uma nova visão. Isso é parte fundamental do aspecto cultural, pois cultura se aprende, se transforma.

Assim sendo, um dos papéis principais que carrega o xamã é o de curar. Isso ocorre através dos ritos que são expressões mágicas e/ou religiosas que tem eficácia tanto instrumental, mudar o mundo, quanto experimental, mudar a mente.

Portanto, o xamanismo pode ser considerado um sistema cultural, pois trabalha o aspecto simbólico, porém também um sistema social, pois destaca papéis onde o xamã é autor principal, mas não o único no grupo e nas atividades sociais. Esse sistema complexo de importante expressão cultural se preocupa com o bem-estar individual e social, com a unificação e a harmonia do todo.

Os rituais compõem um papel importante na construção sócio-política, pois permite alianças, ao mesmo tempo em que se defronta com conflitos causados pela escassez material e 
imaterial na sociedade. Sztutman (2005) discute sobre as relações culturais e, principalmente, sociais e políticas na região das guianas. $\mathrm{O}$ autor (l.c.) observou a formação de alianças por questões materiais, ou seja, econômicas e políticas, como a escassez de mulheres (recursos humanos da região), de recursos naturais (matérias-primas), e de pessoas especializadas que entendam sobre os rituais.

Entretanto, desliza no seu discurso, deixando o leitor visualizar que os rituais transcendem o material e toca o invisível.

\begin{abstract}
"Agora parece geralmente aceito o fato de que a ordenação do mundo, por parte da maioria dos povos da região dos campos e serras das Terras Baixas da América do Sul envolve uma comunicação que percorre uma gama mais ampla de povos e entidades, reais e imaginários, do que aquela que concerne, ao casamento, ao alimento, e as trocas cerimoniais. Essas interações mais amplas, incluem a comunicação com seres do mundo invisível, mas está sendo questionado até que ponto tal comunicação envolve inevitavelmente a predação, no lugar de outros tipos de relacionamento." (Sztutman 2005)
\end{abstract}

É descobrindo e aprendendo a lidar com as forças por trás dos eventos do cotidiano, que o xamanismo encontra sua expressão cultural, sendo a fonte do poder xamânico a própria cultura.

\section{XAMANISMO E CURA}

\section{Medicina tradicional}

Como já relatado, um dos principais aspectos do xamanismo é a cura. Os conceitos de saúde e doença têm relação com a base da cosmovisão, como a transcendência do sagrado, a relação corpo-espírito, a unidade de existência e a vivificação da natureza, e a idealização das relações sociais (Baptista 2012).

Diferente da biomedicina, a maioria dos rituais xamânicos responde a importantes questionamentos cosmológicos e ontológicos, que contextualizam o indivíduo no seu universo, abrangendo suas relações sociais com tudo que está a sua volta nos processos de cura. Neles não existe uma preocupação com objetivo científico e sim de comportamento frente a realidade construído mediante processos sociais e culturais (Langdon 2012).

Outra diferença no processo de cura é que o xamanismo busca também os sinais fora do corpo, procurando entender os motivos da manifestação da doença.

Poderíamos englobá-la em uma linha da medicina tradicional, onde há a manipulação de poderes invisíveis e visíveis, ritos e símbolos para se adquirir a cura.

Considerando o apresentado, o conceito de medicina tradicional refere-se à teorias, crenças e experiências de diferentes culturas, explicáveis ou não. Refere-se a uma série de práticas de saúde que fazem uso de medicamentos a base de plantas medicinais, substâncias animais ou minerais, terapias espirituais, técnicas manuais e exercícios, aplicados isoladamente ou em combinação, com o objetivo de manter o bem estar físico, além de tratar, diagnosticar e prevenir doenças (OMS, 2002). Segundo Albuquerque (1997), nesse contexto, o xamã é a pessoa que mais conhece sobre doenças, técnicas de diagnóstico e cura, e o uso de plantas medicinais.

A representatividade do xamã está descrita pela OMS (2002), como a soma dos conhecimentos habilidades e práticas usadas na manutenção da saúde e na prevenção, diagnósticos e tratamento de doenças físicas ou mentais. A medicina tradicional é também denominada medicina nativa, sendo uma doutrina complexa sobre saúde, doença e as diversas formas de curar. (Baptista 2012).

\section{Harmonia e Unificação do Universo}

Segundo Estrella (1995), nas sociedades pré -coloniais da Amazônia a noção de saúde baseava-se na cosmovisão, uma visão espacial do mundo, no qual havia uma relação entre o sagrado e os seres humanos e a comunidade acontecendo de forma harmônica.

Para Artese (2005) a premissa básica é o reconhecimento que todos fazemos parte da Família Universal e tudo está interligado. O praticante compreende o Espírito Essencial que está dentro dele mesmo, na natureza e em todos os seres. O praticante sabe quem ele é e como se relaciona com o Universo buscando uma harmonia perfeita. Assim, um todo harmonioso não fica doente.

Porém essa harmonia era quebrada quando o indivíduo ou a sociedade desrespeitava as regras, pecavam, o que conduzia a doença, 
castigo divino (Dias 1999), havendo a necessidade de alguém, o xamã, para mediar a ira dos deuses. Este deveria conhecer a doença e investigar suas causas através dos rituais, adivinhações, trabalhando as técnicas empíricas, mágicas, religiosas e racionais para cura.

Nesse sentido a "medicina xamânica" é mais etnológica do que clínica, onde não existe fronteira entre homem e natureza, e sim uma integração entre todos os aspectos (Ramirez 1996). Existe aí o entendimento de que para haver a cura é necessário que o universo esteja em harmonia, não ocorrendo apenas uma cura física, mental e espiritual, mas uma cura do universo, da terra, da história.

Artese (2005) enfatiza a cura como um processo de harmonia e que o equilíbrio no xamanismo é a harmonização dos quatro corpos (físico, mental, emocional e espiritual). Em sua ênfase, identifica a cura que não ocorre apenas no cérebro, mas que ocupa o corpo inteiro.

\footnotetext{
"A consciência não ocupa apenas o cérebro, como o corpo inteiro. Através da consciência você poderá entrar em conexão com cada parte de seu corpo. Para a medicina tradicional, quando uma pessoa recebe uma notícia, que está gravemente doente e que nada pode ser feito, se nenhuma mudança acontecer nessa realidade, a pessoa certamente morrerá. Ao contrário, se as pessoas exploram realidades não ordinárias, alternativas, onde percebem uma saída possível, uma esperança, elas ainda terão uma chance de salvar suas vidas. E essa é a essência da cura xamânica, explorar outras realidades, outros mundos, outros planos, outras dimensões." (Artese 2005).
}

É relevante lembrar que essa cura trabalha as emoções, a confiança, envolve também uma trama psicossomática conhecida pelos "curandeiros" que procuram a participação decisiva da mente no processo de cura, daí a importância dos rituais.

\section{Simbologia}

No processo de cura há toda uma simbologia significante, parecendo o xamã um estranho guerreiro em missão equipado de espadas, santos, punhais, perfumes, ervas, entre outros para restituir a saúde perdida.

Langdon (2012) descreve sobre a performance do ritual, uma realidade de reviver eventos místicos e não apenas reproduzi-los, enfatizando mais uma vez a importância dos símbolos, sendo o ritual um conjunto de substâncias e performance. Além dos símbolos as experiências multissensoriais empregadas com instrumentos rítmicos, roupas, objetos decorativos e canções, são importantes instrumentos canalizadores de percepção nos rituais de cura.

Cada símbolo tem uma capacidade de "armazenagem de informações", desta forma eles guardam um grupo específicos de valores, normas, crenças, papéis sociais $\mathrm{e}$ relacionamentos dentro do contexto cultural do grupo. Helmam (2009) cita vários símbolos rituais e contextualiza alguns significados para certos povos.

A floresta e os animais também participam desse processo de forma efetiva, sendo relevantes inclusive na iniciação do xamã. Paranaguá em seu vídeo "A visão do Xamã"3, conta a história do índio Tirkré que vai ao céu guiado por pássaros simbólicos, em busca do divino. Este índio tem seu ritual de passagem e torna-se curador.

No processo de cura, esses rituais trabalham de forma diferente, mas integrada, buscando como já citado uma unificação harmônica do ser por completo.

McKenna (2006), apaixonado pelo estudo do aspecto ecológico do xamanismo, declara o processo transformador do humano em "curador":

"O neófito passa por uma morte e uma ressurreição simbólica, o que é entendido como uma transformação radical em uma condição sobre-humana, é um senhor do êxtase, pode viajar à vontade no reino do espírito e, mais importante, pode curar e adivinhar. Resumindo o xamã é transformado de um estado profano em um estado sagrado. Ele não somente efetuou sua cura pessoal através dessa transmutação mística; agora ele está investido com o poder do sagrado, e, portanto pode curar também os outros. É importantíssimo lembrar que o xamã é mais do que simplesmente um homem doente ou um louco; ele é um doente que se curou, que está curado, e que deve atuar como xamã para permanecer curado"(Mckenna 2006).

\footnotetext{
${ }^{3}$. Paranaguá, T. 2012. A visão do Xamã. Disponível em www.youtube.com/watchv=zvnaH-M19Ko. Visualizado em julho de 2014
} 
Portanto a cura é o poder sagrado mais importante no xamanismo, carregada de simbologia para alcançar a harmonia do todo individual e coletivo.

\section{CONSIDERAÇÕES FINAIS}

Conceituar xamanismo e aceitar um conceito estático seria interromper uma evolução histórica de espaços diversificados. Entretanto, não é mais aceitável entender o sistema xamânico como primitivo e arcaico.

$\mathrm{Na}$ visão cosmológica ou "cosmovisão", insiro uma concepção dinâmica, onde o contexto sociocultural esteja no centro, onde a harmonia e equilíbrio entre o visível e invisível, material e espacial, real e imaginário esteja fortemente penetrado.

Nessa analise o xamanismo nada mais é do que um sistema sociocultural envolto de significados mágicos religiosos, onde $\mathrm{o}$ indivíduo e a sociedade buscam interpretar os fatos e vivenciar sua interpretação. Para isso não é necessário exatamente a presença de um xamã - não negando a importância de seu papel mediador - mas de um sistema simbólico de práticas e ritos efetivamente aceitos e conclusos para a sociedade.

A cura xamânica passa por um processo complexo de crença e efeito psicossomático, que não resolve apenas problemas físicos, mas envolve uma dinâmica existencial universal.

Sobre esse aspecto, como profissionais da saúde que buscam uma visão transdisciplinar, devemos estudar muito mais, além dos aspectos médicos e biológicos, entender que o xamanismo é muito mais etnológico que científico, buscar fontes da antropologia, das ciências sociais e recebermos as formas empíricas da medicina tradicional.

Desta forma poderemos traçar novos paradigmas e entender um conhecimento que não está apenas na cabeça, mas que além do corpo se discipa pelo universo e trás uma harmonia perfeita com o universo. A cura, a saúde e o equilíbrio não são estáticos, está além de um entendimento visível e natural, mora no "consciente do sobrenatural".

\section{AGRADECIMENTOS}

Ao Dr. Maxim Repetto que contribuiu para esta reflexão.

\section{REFERENCIAS BIBLIOGRÁFICAS}

Albuquerque, U. P. de. 1997. Etnobotânica de uma bebida cerimonial no nordeste do Brasil. Revista Brasileira de Farmácia 78 (4): 86-88.

Andrade, U. M. 2007. O real que não é visto: xamanismo e relação no baixo Oiapoque $(A P)$. Tese de Doutorado em Antropologia da Faculdade de Filosofia, Letras e Ciências Humanas, Universidade de São Paulo, São Paulo.

Artese, L. 2005. Reflexões sobre a cura. Terra Mística: xamanismo e cultura nativa, Porto Alegre. Disponível em http://www.terramistica.com.br. Acesso em 20 de junho de 2014.

Baptista, E. R. 2012. Conhecimentos e práticas de cura em comunidades rurais amazônicas: recursos terapêuticos vegetais. Manaus: Edua/Naea. 374 p.

Castro, E. V. de. 1993. Alguns aspectos da afinidade no dravidianato amazônico. In: Castro, E. V. de; Cunha, M. C. da. (Orgs.). Amazônia: etnologia e história indígena. São Paulo: USP/FAPESP.pp: 149-210.

Castro, E. V. de. 2002. A inconstância da alma selvagem (e outros ensaios de antropologia). São Paulo: Cosac \& Naify. 552p.

Cunha, M. C. da. 1998. Pontos de vistas sobre a floresta Amazônica: xamanismo e tradução. Mana 4 (1): 7-22.

Dias, P. S. 1999. A Farmácia e a História. Uma introdução à História da Farmácia, da Farmacologia e da Terapêutica. Lisboa. Disponível em: http:// www.ufpi.br/subsiteFiles/lapnex/arquivos/files/ Farmacia-e-Historia.pdf. Acesso em: 13 de junho de 2014.

Helman, C.G. 2009. Cultura, saúde e doença. Trad: Eliane Mussmich, $5^{\mathrm{a}}$ ed. Porto Alegre: Artmed Editora, $432 p$.

Langdon, J. 1996a. Performance e preocupações pós modernas em antropologia. In: Teixeira, J. G. L. C. (org). Performáticos, performance e Sociedade. Brasília: Editora Universidade de Brasília, 1996. p. 2329.

Langdon, E. J. M. 1996b. Xamanismo no Brasil: Novas Perspectivas. Florianópolis: Ed. UFSCAR. 367p.

Langdon, E. J. 2012. Rito como conceito-chave para a compreensão de processos sociais. In: Langdon, E. J.; Pereira, E. L. (Org.). Rituais e performances: iniciações em pesquisa de campo. Florianópolis: UFSC/Departamento de antropologia. p. 17-22.

Mckenna, T. O xamã e o mundo invisível. Disponível em http://www.terramistica. com.br/index.php? add $=$ Artigos $\&$ file $=$ article $\&$ sid $=478 . \quad$ Acesso em 30.06.2014.

Organização Mundial de Saúde (OMS) 2002. The World Health Report: Saúde mental: nova concepção, nova esperança. $25 \mathrm{p}$. 
Ramirez, G. Z. 1996. La selva: una gran planta medicinal. In: Pavan, C. Uma estratégia latina americana para a Amazônia. Brasília: MMA; São Paulo: Memorial, p.257-263.

Sams, J. 1997. As cartas do caminho sagrado - A lição dos Xamas. Editora Rocco. 3a ed. 356 p.

Sztutman, R. 2005. Sobre a ação xamânica. In: Gallois, D. T. Rede de Relações das Guianas. São Paulo: Associação Editorial Humanistas: Fapesp. 